DOI: 10.20472/AHC.2019.005.005

\author{
NEBOJŠA JANIĆIJEVIĆ \\ University of Belgrade, faculty of Economics, Serbia
}

\title{
THE IMPACT OF NATIONAL CULTURE ON LEADESRHIP IN SOCETY AND ORGANIZATIONS: WHY DO SERBS LOVE AUTHORITARIAN LEADERS
}

\begin{abstract}
:
The paper analyses the impact of national culture on leadership and leadership styles. It has been determined that national culture impacts leadership and leadership styles by defining the meanings that both the leader and his followers ascribe to the reality that surrounds them. The analysis includes the impact that the dimensions of national culture, identified in the Geert Hofstede's and GLOBE's researches, have on leadership. The paper analyses the impact that the dimensions of national culture have on two main dimensions used to differentiate leadership styles: authoritarianism-participative orientation and task orientation-people orientation. It has been determined that power distance and individualism-collectivism as well as uncertainty avoidance and assertiveness decisively impact the selection between authoritarian and participative leadership styles. The national culture's "masculinity"-“femininity" dimension, as well as gender equality, performance orientation, people orientation, and future orientation correlated with it, impact the selection between people orientation and task orientation. In certain contexts, a high uncertainty avoidance also impacts this leadership dimension. By intertwining two leadership styles' dimension, four leadership styles are created, as well as cultural contexts in which each of the styles is favoured, preferred, and thereby more effective. Serbian national culture, with its assumptions and values, implies using of authoritarian people-oriented style.
\end{abstract}

\section{Keywords:}

leadership, leadership styles, national culture, national culture dimensions, Serbia, GLOBE research

JEL Classification: M10, M14 


\section{Introduction}

Among other implications, globalization has made national culture and its impact on economy and management the center of attention. Globalization is understood as the process of weakening of borders between world states, and the consequential intensification of the flow of goods and services, people, capital, technology, information, and ideas between them (Daft, 2010, p. 13). Globalization leads to companies' ever greater exposure to different national cultures, and thereby introduces multiculturalism to their business operations. National culture imposes certain assumptions, beliefs, norms and attitudes on its members, and thereby determines their understanding of reality and their behavior in it. National culture is defined as "mental programming: the pattern of thinking, feeling, and acting that every person acquires in their childhood and then applies throughout their lifetime" (Hofstede, 2001, p. 25) or as "a set of assumptions, values, norms and attitudes manifested through symbols developed by a national community which help its members determine the meaning of the world around them and how to behave in it" (Janićijević, 2013).

Companies face with cultural differences both outside and inside (Dessler, 2013). Companies that perform in markets of different countries face with significant differences in consumers' assumptions, beliefs, and values, which carries implications on their needs as well as on their consumption habits. Within the companies themselves, cultural diversity of workforce is significantly increasing, even in those that do not operate outside of the boarders of their own country (Thomas \& Peterson, 2018).. Employees more and more often come from different national cultures, carrying their own beliefs, values, behavior norms, and attitudes. Thus, a situation is created where a company's employees must work together with their coworkers and managers, and in that process, they are starting from completely different assumptions and values guiding their behavior. This multiculturality or cultural diversity of workforce can be useful, particularly when the values and norms brought by the members of different cultures are combined in just the right way (Sweeney \& McFarlin, 2015; Hofstede, 2002). However, when cultural diversity is not treated in the right way, it can create conflicts and misunderstanding, and may have negative consequences on the organization's functioning. Therefore, it is clear that understanding of the impact of national culture on management and organizational behavior is a necessary prerequisite for effective management of cultural differences in contemporary companies, and thereby also for an effective management within them.

Leadership is one of the most important topics in management and organizational behavior, because leaders very often have a decisive impact on business operations and company performance. Leadership, understood as the process whereby an individual influences a group of individuals to achieve a common goal (Northouse, 2019), is especially sensitive to the impact of national culture and cultural differences. Since the essence of leadership is the process of interaction and an individual's influence on the group he/she leads, it is clear that the 
effectiveness of this process depends on the compatibility of the ways in which the leaders and their followers understand the world around them and the very process of leadership in that world. In order for leaders to be able to impose their interpretation of reality on their followers and also a desirable behavior in it, the followers must first understand the leader. For that matter, we do not speak of a common language, but of mutual understanding of the meanings of basic occurrences and relationships in a society. The leaders will not be able to impose their view of the existing and the vision of the new reality to their followers if the followers do not share the same understanding of the basic occurrences in society as the leaders do (Sweeney \& McFarlin, 2015).

Since understanding of the basic social issues is based on the assumptions, beliefs and values of national culture, it is clear that leadership is conditioned by national culture. In different cultures, leaders will lead their followers differently simply because they both start with different views on the reality in which they live (Jaeger, 1986). People in authoritarian cultures expect an authoritarian leader, while democratic leaders who seek their followers' participation in decisionmaking are more successful in the cultures dominated by the assumptions about the need to equalize the power in society. If a leader coming from an authoritarian culture, and carrying the assumptions on unequal relations between people, wants to impose himself as the leader to the followers coming from a culture that seeks equalization of power, their relationship will be difficult and there is a slim chance that such leader will be effective in that particular situation: the followers will simply not understand the leader, and the leader will not understand the followers. The reverse is true as well.

The research into the impact of national culture on leadership is most often observed through the impact of cultural assumptions and values on leadership style, that is, on the leaders' behavior (Browaeys, Price, 2015). Two most often used criteria or dimensions according to which different styles of leadership are differentiated are: (1) Authoritarianism of leader, i.e. the degree of participation of the followers in decision-making; (2) People orientation or task orientation in solving organizational problems (Northouse, 2019; Yukl, 2013; Ashkanasy, Wilderom, Peterson, 2000). Therefore, leaders differ by the degree in which they autonomously make decisions or in which they allow participation of their followers (employees) in decision-making, as well as by the fact whether they strive to achieve the goals through formal components, structure, roles, procedures and tasks or rather through informal components, interpersonal relationships, influence on people and the like. Since there are two dimensions of leadership style with two poles each, it is clear that we will get four possible leadership styles. The basic leadership style types may be observed in the following figure: 
Figure 1: Leadership styles

\begin{tabular}{|r|c|c|}
\hline & Authoritarism, low participation & $\begin{array}{c}\text { Egalitarianism, high } \\
\text { participation }\end{array}$ \\
\hline $\begin{array}{r}\text { Orientation to tasks } \\
\text { and work structure }\end{array}$ & TUTHORITARIAN LEADERSHIP & PARTICIPATIVE LEADERSHIP \\
\hline $\begin{array}{r}\text { Orientation to people } \\
\text { and social structure }\end{array}$ & PEOPLE ORIENTED & PEOPLE ORIENTED \\
PARITARIAN LEADERSHIP & PARTICIPATIVE LEADERSHIP \\
\hline
\end{tabular}

The aim of this paper is to present the most important impacts of national culture on leadership that the researchers have so far discovered and to offer a new theoretical framework for systematization of compatibilities between national culture dimensions and leadership styles. The paper will fist explain implications of national culture dimensions on leadership and leadership styles as presented in the two key researches in the field: the research of Geert Hofstede and the GLOBE research. In the second part of the paper, the implications will be summarized in a matrix with four combinations of national culture dimensions and four leadership styles which they imply and which will be effective in those national cultures.

\section{The Overview of the Impact of National Culture Dimensions on Leadership Style}

With respect to the implications of individual national culture dimensions on leadership, two researches stand out: the research of Geert Hofstede and the GLOBE research. Hofstede's research is a fundamental investigation into cross-cultural management and also into the impact of national culture on management. We may unreservedly say that Hofstede is the founder of cross-cultural research in management. Just like the Hofstede's research, the GLOBE research is also a very exhaustive empirical research aimed precisely at discovering the impacts of national culture on leadership, and its very name speaks of it: Global Leadership and Behavior Effectiveness. Both researches have identified certain dimensions of national culture and have provided us with a certain insight into the implications of these dimensions on leadership.

\subsection{Geert Hofstede's Research}

At the end of 1970s, Hofstede (2001) had conducted an enormous empirical research on the differences between national cultures and had, thereby, set the foundations for the cross-cultural research in management. In his huge research, he had identified four dimensions of national culture according to which national cultures differ, and then he investigated the impact of those dimensions on different aspects of management and organizational behavior. Hofstede managed to quantify the positions of cultures in each dimension, and he thereby enabled himself and other researchers who followed him to investigate the impact of each dimension of national culture on different components of management. One of the most important components of organization and management impacted by national culture is leadership, and Hofstede's research has provided interesting ideas about how leadership differs in different national cultures. In further text, the 
impact of each of the four main dimensions of national cultures on leadership will be described in the way Hofstede had described it.

Power distance is the national culture dimension that perhaps has the most powerful and most direct impact on leadership. This national culture dimension shows how a society has resolved the fundamental problem of the distribution of power. Power distance is the degree in which a society accepts the fact that power is unequally distributed in the society, institutions and organizations (Hofstede, 2001). In other words, power distance shows the degree in which the members of one national culture consider that it is normal and expected that power is unequally distributed. In cultures with high power distance, its members consider that unequal distribution of power in society is something natural, useful and the only possible. In cultures with low power distance, its members consider that they should strive to equalization of power in society and its organizations. Hence, it is natural that the leaders in the cultures with high power distance strive to authoritarian leadership styles, while the leaders in the cultures with low power distance strive to participative or democratic leadership styles (Yukl, 2013, Hofstede, 2001). In cultures with high power distance, the followers expect authoritarian behavior of the leader, and they do not expect to be included in decision-making. They consider it natural for the leaders to make all the decisions and completely take the responsibility and the risks on themselves. The leaders often practice paternalistic behavior in which they, besides concentrating the power, take care of the interests of their followers, so their style takes the shape of benevolent authoritarianism (Likert,1961). In cultures with low power distance, the followers expect and require participation in decision-making from the leader. Therefore, the leaders practice participative leadership style with the focus on the development of their followers, but they also share the responsibility with the followers. The research has shown that not only are the authoritarian leaders more frequently present in the high power distance cultures, but are also more effective in such cultures than the democratically focused leaders. One study has shown, for example, that workers' productivity in Mexico (high power distance index) was higher when the leader applied authoritarian-benevolent leadership style, than when the leader applied democratic leadership style. In American culture (low power distance index), productivity was the highest when the leader applied participative leadership style (Schuler, et al., 2001).

Uncertainty avoidance is a national culture dimension which, according to Hofstede (2001), shows the attitude of the culture's members towards changes, uncertainty, risk, novelties, and diversity. In cultures with high uncertainty avoidance, their members do not like and feel bad in new and uncertain situations. They strive to minimize the level of uncertainty by preventing the situations that generate uncertainty from happening, such as changes, diversity, vagueness, and the like. In such cultures, tradition, hierarchy, discipline and social norms are highly valued, since all of the stated actually decreases uncertainty in society. On the other hand, in cultures with low uncertainty avoidance changes are preferred, risk taking is appreciated, and entrepreneurship 
and innovativeness is encouraged. The society with such culture is usually very open for new experiences, youth is respected, and differences are accepted.

A high level of uncertainty avoidance in a culture leads to authoritarian leadership, while a low level of uncertainty avoidance leads to participative leadership (Yukl, 2013). Namely, the leading of people in the situations of acceptance of changes, vagueness, diversity and novelties implies participative leadership style, since the leader in such situations must delegate the power to the followers. On the other hand, the participative leadership style in itself carries uncertainty, since one can never know what will the followers' decision be if they have already been given a certain amount of power in decision-making. Therefore, low uncertainty avoidance and participative leadership style are mutually supportive. On the other hand, high uncertainty avoidance implies authoritarian leadership style. Protection from uncertainty through norms, tradition, hierarchy and rules implies authoritarian leadership style. Authoritarian leadership style does not stand uncertainty. Therefore, high uncertainty avoidance and authoritarian leadership style are mutually supportive.

Uncertainty avoidance does not impact only the selection between authoritarian and participative leadership styles, but also the selection between people orientation and task orientation in the leader's behavior. According to Hofstede, high uncertainty avoidance leads to the task oriented leadership. Namely, people reduce uncertainty through orientation on structures, tasks, and rules, as well as though relying on formalization, specialization, and standardization. In such cultures, it is believed that if the processes in the society or organizations are prescribed in advance and then enforced with discipline, the uncertainty will disappear. The consequence will be the leadership oriented to tasks and structures. The leader is expected to be reliable, punctual, and precise rather than innovative and charismatic. However, Hofstede overlooked that formalization and orientation to structures and tasks was just one of the ways to reduce uncertainty. Another way for the people to reduce uncertainty is to surrender their destiny to the leader. The leader in such cultures, usually collectivistic ones, has the task to protect his/her followers from uncertainty, and in return, the followers give the leader their complete loyalty and put all the power in his/her hands. The consequence is, of course, authoritarian people oriented leadership. The leader is expected to be omnipotent, and the leader's confidence is highly appreciated. The followers usually hold an idealized image of the leader as long as the leader protects them from uncertainty. If it happens that the leader is no longer able to solve problems and protect the followers, he/she is quickly and easily replaced. Consequently, it follows that high uncertainty avoidance leads to task orientated behavior of the leaders only in individualistic cultures, while in collectivistic cultures high uncertainty avoidance leads to people orientation. By summarizing the stated implications, we may construct the following matrix: 
Figure 2: The impact of uncertainty avoidance and individualism-collectivism on leadership styles

\begin{tabular}{|r|c|c|}
\hline & High uncertainty avoidance & Low uncertainty avoidance \\
\hline $\begin{array}{r}\text { Individualistic } \\
\text { culture }\end{array}$ & $\begin{array}{c}\text { AUTHORITARIAN LEADERSHIP - } \\
\text { TASK ORIENTED }\end{array}$ & PARTICIPATIVE LEADERSHIP \\
\hline $\begin{array}{r}\text { Collectivistic } \\
\text { culture }\end{array}$ & $\begin{array}{c}\text { AUTHORITARIAN LEADERSHIP - } \\
\text { PEOPLE ORIENTED }\end{array}$ & PARTICIPATIVE LEADERSHIP \\
\hline
\end{tabular}

Individualism-collectivism is a national culture dimension which shows how has a society resolved the fundamental problem of the relationship between an individual and the collective (Hofstede, 2001). Collectivistic cultures are those that prioritize the collective, while individualistic cultures are those that prioritize the individual. In collectivistic cultures, the collective is tightly bound, and the relationships between the members of the group are very close and emotional. In such cultures, it is considered that individuals have the right to expect that the collective that they belong to will take care of them, and in return, they will be completely loyal to the collective and its leader. The responsibility for the wellbeing of individuals rests on the collective they belong to. In individualistic cultures, the social structure is loose, and the relationships between the members of the group are less close and emotional. The responsibility for the wellbeing of individuals rests primarily on themselves, and an individual has no right to expect from the collective to take care of him/her. Desirable traits of leaders in highly individualistic countries are autonomy, uniqueness, and independence, while in highly collectivist cultures these are precisely the traits that a leader must not have (Yukl, 201). Individualism implies that individual goals are above organizational goals, and that the relationship between an individual and the organization is rational and calculative. On that grounds, an assumption is established that the leader leads and guides the organization according to his/her personal decisions and preferences. In collectivistic cultures, however, the relationship between an individual and the organization is ethical and emotional, rather than rational, so the leader is expected to lead the organization according to the interests of the entire organization.

Individualism-collectivism impacts the degree of authoritarianism or democracy in leadership. In individualistic cultures, everyone is responsible for one's own destiny, and autonomy and independence are highly appreciated, hence the leader will have difficulties in trying to impose an authoritarian leadership style. The people expect to be included in the decision-making process. Conversely, as previously noted, people in collectivistic cultures expect the leader to take care of them and protect them from uncertainty, so they offer their complete obedience and loyalty in return. Thus, it is no wonder that, in collectivist cultures, authoritarian leadership styles are favored more than participative leadership styles. It is also revealed that collectivist cultures are more suitable than individualistic cultures for emergence of transformational or charismatic leadership (Dickson, et al., 2003; Den Hartog et a., 1999). The reason for this is simple: in collectivist cultures, people are more prone to identify themselves with the group and the common 
vision or goals of the group, usually shaped by a charismatic leader. In such cultures, people are more ready to put the collective interests before individual ones, which creates a suitable foundation for a charismatic leader to, by shaping common interests, lead the followers into the new and unknown. In individualistic cultures, it is harder for a charismatic leader to emerge, since all people are predominantly driven by their own interests and rational calculations. Therefore, transactional leadership is more likely to occur in such cultures. Another important leadership dimension impacted by the individualism-collectivism dimension is people orientation versus task orientation. Based on the description of collectivism, it is clear that leaders in such cultures must be people oriented and enforce their leadership primarily through people, while structure and tasks are second in importance. Conversely, task oriented leadership style is most often preferred in individualistic culture.

Masculinity-femininity dimension of national culture shows how a society has solved the issue of gender relations (Hofstede, 2001). Masculinity cultures favor the traits and behaviors that are usually ascribed to the male sex, such as assertiveness, aggressiveness, speed, strength, goal orientation, effectiveness, etc. In such cultures, problem solving, achievement of results and effective tasks completion are highly valued. Showing emotions is unacceptable, especially when men are concerned, and interpersonal relationships are more formal, reserved, and less close. Masculinity cultures are "doing" cultures, and the value of a person is determined based on the results the person has achieved, especially in acquiring material goods. An implicit assumption in masculinity cultures is that the man, with the help of technology, can subdue nature for his own wellbeing. Femininity cultures are the ones dominated by the traits and behaviors that are usually considered "female": caring for others, building of social relations, wellbeing, harmony, and balance. Femininity cultures are dominated by the implicit assumption that the man should be in harmony with nature. Femininity cultures are "being" cultures in which the value of a person is proven based on the person's existence and interpersonal relationships with other people. Femininity cultures are not entrepreneurial, and they do not value success, results, and achievement to the extent that masculinity cultures do. Expressing emotions is acceptable, and interpersonal relationships are closer and more emotional. The implications of masculinityfemininity dimensions of national culture on leadership are important, and they primarily relate to the orientation to tasks or people. The leaders in masculinity cultures more often apply task oriented style, while the leaders in femininity cultures apply people oriented style, with their primary concern being harmonization of interpersonal relationships within the group, as well as the needs of the members of the group or organization. In masculinity cultures, the leader is usually aggressive and assertive, and has typical male qualities. In femininity cultures, the leader is less visible, more prone to consensus, and has both male and female qualities. In masculinity cultures, the leader is a hero, while in femininity cultures, the leader is closer to the common man. In masculinity cultures, the need for achievement is more prominent, so the leaders are significantly more motivated by this type of needs (Dorfman, 2003). 


\subsection{The GLOBE Research}

The second exhaustive and relevant research of the impact of national culture on leadership is the result of a large international research project "Global Leadership and Organizational Behavior Effectiveness". This research project was conduced in 60 world counties under the guidance of professor House from the U.S. The main goal of the research was to determine if leadership is conditioned by national culture or it is universal in character. In other words, is leadership the same in all national cultures or is the effective leadership style different in different national cultures? The research has produced many important results such as, for example, identifying of universally desirable leader's traits, universally undesirable leader's traits, and those leader's traits that are different in different cultures. For this paper, the most important result of the GLOBE research is identifying of nine national culture dimensions and their implications on leadership. These nine dimensions are the following: power distance, uncertainty avoidance, societal collectivism, in-group collectivism, future orientation, gender egalitarianism, performance orientation, humane orientation, and assertiveness House et al., 2004; House\& Javidan, 2004). From the very names of these dimensions it is transparent that they significantly overlap with the dimensions identified by Hofstede. But, since there are nine national culture dimensions in the GLOBE classification, this means that some of them are elaborated in more detail than the ones identified by Hofstede and there are some new dimensions. However, based on their meanings and contents, we may easily relate even these new ones with the Hofstede's dimensions. The dimensions identical in both researches in their content and name are power distance and uncertainty avoidance. The Hofstede's individualism-collectivism dimension is elaborated into two dimensions: societal collectivism and in-group collectivism. The difference between the two dimensions is the level where collectivism is manifested: while societal collectivism refers to collectivism in Hofstede's sense manifested at the level of the entire society, the in-group collectivism refers to collectivism manifested at the level of a family, social group or organization. Nevertheless, the essence of collectivism in the GLOBE research remains the same as in the Hofstede's research, Therefore, we may conclude that the implications of power distance, uncertainty avoidance and collectivism (at both levels) on national culture are the same in both researches.

The remaining national culture dimensions in the GLOBE research can be more or less directly related to Hofstede's masculinity-femininity dimension, and thereby also to their implications on leadership.

Gender egalitarianism shows the extent to which a society minimizes the differences between the gender roles and generally the role of gender in human behavior (House et al., 2004). Although gender roles in society are different in all cultures, these differences are smaller in cultures with high gender egalitarianism than they are in the cultures with high gender egalitarianism. In cultures with high gender egalitarianism, women are to a larger extent treated as equal to men, and such societies generally offer greater chances to women to fully develop and participate in 
business and society. In cultures with low gender egalitarianism, the roles of men and women are more greatly differentiated, and gender inequality at work and in the society is higher. It is logical that the cultures with low gender egalitarianism consider typical female traits, such as empathy, support, and intuition, as undesirable for a leader, while "male" traits and behaviors, such as asertiveness, strictness and firmness, are considered desirable. The researches have shown that the leaders in cultures with high gender egalitarianism should apply participative style, supportive style and people orientation, that the leaders in cultures with low gender egalitarianism should not display precisely such behaviors: they should use direct, confrontational methods of influence, unlike the leaders in cultures with high gender egalitarianism, who should use refined, concealed and indirect methods of influence. Based on all previously stated, it is clear that there is a clear correspondence between the cultures with high gender egalitarianism and femininity cultures, as well as between the cultures with low gender egalitarianism and masculinity cultures. The consequence is that we may conclude that cultures with low gender egalitarianism favor task orientation of leaders, while cultures with high gender egalitarianism favor people orientation in leadership.

Performance orientation is a national culture dimension which shows to what extent are the results orientated behavior and the results themselves incited and rewarded. In cultures with high performance orientation, people are incited to set and achieve challenging goals, accomplishment is highly appreciated, and people are valued according to what they do and what they have achieved instead of who they are and what they are with respect to national, family or gender affiliation. It is perfectly logical that task oriented leadership style is effective in cultures with high performance orientation, while people oriented leadership style is effective in cultures with low performance orientation. In cultures with high performance orientation, leaders are expected to be effective and to achieve the set goals. Leaders in such cultures set high goals and develop standards and plans with detailed time and task schedules that the followers should perform. They choose the members of the team according to their competencies and talents, rather than according to friendship relations. There is an obvious correlation between the cultures with high performance orientation and Hofstede's masculinity cultures, and also between the cultures with low performance orientation and Hofstede's femininity cultures.

Humane orientation shows the degree in which society nurtures people's wellbeing and incites one's personal sacrifice for the wellbeing of other people (Northouse, 2019; Yukl, 2013, House et al., 2004). Cultures with high humane orientation highly value altruism, compassion, kindness, benevolence and generosity in interpersonal relationships. In such cultures, leaders are expected to respect their followers' feelings and needs, as well as to help them, through mentorship, achieve the common goals. Leaders are also expected to guide and help the followers by giving instructions, whereby the leaders show high level of tolerance, patience and benevolence towards their followers. Therefore, it is clear that cultures with high humane orientation will favor participative leadership and also people oriented leadership, and not task oriented leadership. 
This national culture dimension in the GLOBE research, as well as the previously described dimension, correlates to masculinity-femininity national culture dimension. A high level of humane orientation implies that it is in fact a femininity culture, and a low level of humane orientation implies that it is in fact a masculinity culture.

Assertiveness is a national culture dimension which shows to what extent a society values and expects assertive, direct, and aggressive behavior. In cultures with high degree of assertiveness, the leader is expected to be direct, to confront if necessary, to take risks, and to quickly and independently make decisions (Northouse, 2019; Yukl, 2013, House et al., 2004. In cultures with low degree of assertiveness, people are expected to be mild, timid, cautious, indirect, and even submissive in interpersonal relations with other people; the leader is then expected to be gentle towards the followers, to bear in mind their dignity, and to be indirect and mild in critiques. It is clear that a high level of assertiveness favors task orientation, while a low level of assertiveness favors people orientation. Likewise, it may be concluded that a high level of assertiveness leads to authoritarian leadership style, while a low level of assertiveness is associated with participative leadership style. We may conclude that this national culture dimension also correlates to Hofstede's masculinity-femininity dimension in the way that a high level of assertiveness corresponds to a high level of masculinity in national culture, and that a low level of assertiveness corresponds to a high level of femininity in national culture.

Future orientation shows the extent to which the members of society are incited to think, plan and invest in the future, delay pleasure, and actively prepare for the future. In cultures with low future orientation, people live more in the present moment, they are spontaneous and they do not plan the future too much (Northouse, 2019; Yukl, 2013, House et al., 2004). We may assume that cultures with high future orientation correspond to masculinity cultures, while cultures with low future orientation correspond to femininity cultures. Due to this, we may conclude that task oriented leadership style will be effective in cultures with high future orientation, while people oriented leadership style will be effective in cultures with low future orientation.

\section{The Matrix of Effective Leadership Style in Different National Cultures}

Summarizing of the impact of different national culture dimensions on leadership styles and leaders' behavior enables us to discern several different cultural contexts that require different leadership styles and in which different leadership styles are effective. The previous analysis of the impact of the four Hofstede's national culture dimensions and the nine GLOBE Project's national culture dimensions on leadership styles has shown that the impact is mainly expressed in two leadership dimensions: authoritarian-participative and people-oriented-task-oriented. Since we have demonstrated that these two leadership dimensions can be crisscrossed in a single matrix and that four leadership types can be obtained, now we may show how different national culture dimensions favor the selection of one out of the four described leadership styles. 
Power distance and individualism-collectivism decisively impact the preferences regarding the choice between authoritarian and participative leadership styles. Collectivistic cultures and/or cultures with high power distance prefer authoritarian style leaders, while individualistic cultures and/or low power distance prefer participative style leaders. The impact of these two dimensions is particularly strong when they are acting at the same time, that is, when collectivism is combined with high power distance, and individualism with low power distance. The preferences towards authoritarian leadership style in collectivistic cultures are additionally amplified in the presence of high uncertainty avoidance, because the national culture members expect that the leader of the collective will protect them from uncertainty. The preferences towards participative leadership style in individualistic cultures with low power distance will be additionally amplified in the presence of low uncertainty avoidance, because the leader is, in such circumstance, able to tolerate uncertainty that accompanies the followers' participation. A low degree of assertiveness also strengthens the preferences of a participative leadership style, while a high degree of assertiveness leads toward an authoritarian leadership style.

Preferences regarding the selection between task oriented and people oriented leadership styles are determined by Hofstede's masculinity-femininity national culture dimension, as well as the GLOBE dimensions that correlate to it: gender egalitarianism, performance orientation, humane orientation, assertiveness, and future orientation. A high masculinity level in a national culture, low gender egalitarianism, high performance orientation, low humane orientation, high assertiveness and high future orientation lead to the situation in which task orientation is preferred, probable, and more effective leadership style in the society and its organizations. In addition, if all the stated national culture dimensions act in conjuncture, which may be assumed having in mind their nature and content, their impact will be amplified. Also, high uncertainty avoidance in individualistic cultures also favors task orientation of leaders. High level of femininity, high gender egalitarianism, low performance orientation, high humane orientation, low assertivenes and low future orientation lead to the situation in which people orientation is preferred, probable, and more effective leadership style in the society and its organizations. Again, if all the stated national culture dimensions act simultaneously and in the same direction, their impact will be amplified. People orientation will also be supported in collectivistic cultures, especially in the circumstances of high uncertainty avoidance.

When we crisscross the impact of national culture dimensions on two leadership style dimensions, we obtain the matrix shown in Figure 3. 
Figure 3: The impact of national culture dimensions on leadership styles

\begin{tabular}{|c|c|c|}
\hline & $\begin{array}{c}\text { High power distance, } \\
\text { Collectivism (in-group, } \\
\text { societal), } \\
\text { High uncertainty } \\
\text { avoidance } \\
\text { High assertiveness }\end{array}$ & $\begin{array}{c}\text { Low power distance, } \\
\text { Individualism (in-group, } \\
\text { societal) } \\
\text { Low uncertainty } \\
\text { avoidance } \\
\text { Low assertiveness }\end{array}$ \\
\hline $\begin{array}{r}\text { masculinity, low gender } \\
\text { egalitarianism, high } \\
\text { assertivenes, high } \\
\text { performance orientation, } \\
\text { low humane orientation, } \\
\text { high future orientation, } \\
\text { individualism with high } \\
\text { uncertainty avoidance }\end{array}$ & $\begin{array}{l}\text { TASK ORIENTED } \\
\text { AUTHORITARIAN } \\
\text { LEADERSHIP }\end{array}$ & $\begin{array}{l}\text { TASK ORIENTED } \\
\text { PARTICIPATIVE } \\
\text { LEADERSHIP }\end{array}$ \\
\hline $\begin{array}{r}\text { femininity, high gender } \\
\text { egalitarianism, low } \\
\text { assertivenes, low } \\
\text { performance orientation, } \\
\text { high humane orientation, } \\
\text { low future orientation, } \\
\text { collectivism with high } \\
\text { uncertainty avoidance }\end{array}$ & $\begin{array}{l}\text { PEOPLE ORIENTED } \\
\text { AUTHORITARIAN } \\
\text { LEADERSHIP }\end{array}$ & $\begin{array}{c}\text { PEOPLE ORIENTED } \\
\text { PARTICIPATIVE } \\
\text { LEADERSHIP }\end{array}$ \\
\hline
\end{tabular}

Authoritarian task oriented style will be favored, probable and effective in national cultures with high power distance, high masculinity and high collectivism. This style, however, may also be expected in individualistic cultures, but only if uncertainty avoidance is high. Also, this style is supported in national cultures with low gender egalitarianism, high performance orientation, high assertiveness, high future orientation and low humane orientation.

Authoritarian people oriented style will be preferred and effective in collectivistic national cultures with high power distance and high uncertainty avoidance. Also, this style is supported in national cultures with high gender egalitarianism, low performance orientation, low assertiveness, low future orientation and low humane orientation.

Participative task oriented style will be supported and effective in masculinity and individualistic national cultures that also have low power distance and low uncertainty avoidance, low gender egalitarianism, high assertivenes, high performance orientation, low humane orientation, and high future orientation. 
Participative people oriented style will be supported and effective in femininity and individualistic national cultures with low uncertainty avoidance and low power distance, that also have high gender egalitarianism, low assertiveness, low performance orientation, high humane orientation, and low future orientation.

Hofstede included former Yugoslavia in his research and this why we have the data on its national culture. When Yugoslavia fell apart in the 1990s and when several smaller states were formed, this broke the Yugoslavia-sample into three sub-samples: Serbia, Croatia, and Slovenia. Thereby we got the national culture indexes for these three countries, which are very similar, as it would be expected. Serbian national culture has the following values sorted by the dimensions:

Table 1. Serbian National Culture Indexes

\begin{tabular}{|l|r|c|}
\hline \multirow{2}{*}{ National Culture Dimension (min-max index) } & \multicolumn{2}{|c|}{ Republic of Serbia } \\
\cline { 2 - 3 } & index & rank (1-74) \\
\hline Power Distance - PDI (11-104) & 86 & 8 \\
\hline Uncertainty Avoidance - UAI (8-112) & 92 & $11-13$ \\
\hline Individualism - IND (6-91) & 25 & $53-54$ \\
\hline Masculinity - MAS (5-95) & 43 & $47-50$ \\
\hline
\end{tabular}

Source: Hofstede, G., (2002). Images of Europe: Past, present and future. In: Warner, M. \& Joynt, P. (Eds). Managing across cultures, (pp. 89-103). London: Thomson.

Since Serbia has the combination of collectivism, high power distance, high uncertainty avoidance and high femininity, it is obvious that authoritarian people oriented style is dominant within Serbia's framework. High power distance and extremely high collectivism imply that the members of Serbian national culture prefer authoritarian leaders. This is enhanced by high uncertainty avoidance, due to which the members of this culture expect that the authoritarian leaders will protect their followers from uncertainty. Femininity joined with collectivism develops support for people oriented leadership, and not for task oriented leadership.

The GLOBE research did not include Serbia, so we have no data about the other national culture dimensions identified in the said research. Since Serbia has a relatively high femininity, we may assume that humane orientation dimension would also be high, but also that performance orientation, future orientation and assertiveness dimensions would be low. This implies the presence of people orientation in leadership styles in Serbian national culture.

\section{Conclusions and limitations of the study}

The paper analyses the implications of national culture on leadership in organizations. The main research issue that we strive to resolve is if and how does a national culture condition the leaders' behavior so that different leadership styles are preferred in different national cultures and also 
that these leadership styles are more effective than other leadership styles? The national culture dimensions identified by Geert Hofstede in his research and also the national culture dimensions identified in the GLOBE research have been used as the basis for our analysis. Since the literature on leadership usually differentiates the leadership styles according to two dimensions (authoritarianism-participative orientation and task-orientation-people-orientation), therefore, the analysis of the impact of national culture has been focused precisely on these two dimensions and the selection of leaders with respect to their behavior in the two said dimensions.

The analysis has shown that power distance and collectivism as well as uncertainty avoidance and assertiveness decisively impact the selection between authoritarian and participative leadership styles. Thus, the leaders with authoritarian style will be more likely and effective in a national culture with high power distance, high collectivism, high uncertainty avoidance and high assertiveness, while the leaders with participative style will be more probable and effective in a national culture with low power distance, low collectivism, low uncertainty avoidance and low assertiveness. The selection between people orientation and task orientation is impacted by masculinity dimension of national culture, as well as the correlated gender egalitarianism, humane orientation, performance orientation and future orientation. In certain contexts, high uncertainty avoidance also impacts this leadership dimension. In national cultures with high masculinity, high performance orientation and high future orientation and with low gender egalitarianism and low humane orientation, the leaders with task orientation will be more common and effective. In national cultures with high femininity, high gender egalitarianism and high humane orientation and with low performance orientation and low future orientation, the leaders with people orientation will be more common and effective. By crisscrossing these two dimensions of leadership styles, we have obtained four leadership types and cultural contexts in which each style is favored, preferred, and thereby more effective. Serbian national culture, with its assumptions and values, implies the use of people oriented authoritarian style.

The paper also has limitations that concern primarily its theoretical and explorative nature. Relying on the previous research, the paper generates the assumptions of the impact of national culture on leadership, but it does not prove them. This is why this paper is a good basis for designing of a future cross-cultural study that would be able to confirm or refute the results of this analysis. Also, the limitation of the paper is that our analysis has included only the national culture dimensions established by Hofstede's and the GLOBE researches, and has ignored other dimensions identified by other researchers. The reason for this is that such analysis would be overly complicated and difficult to perform, and we would hardly be able to clearly present its results. 


\section{References}

Ashkanasy, N., Wilderom, C. \& Peterson M. eds., 2000. Handbook of organizational culture \& climate. Thousand Oaks: Sage

Browaeys, M., \& Price, R. (2015). Understanding cross-cultural management. Harlow, VB: Pearson.

Daft R. (2010) Organizational theory and design. Mason, OH: Cengage Learning;

Den Hartog, D.N., House, R.J, Hanges, P.J., Ruiz-Quintanilla, S.A., Dorfman, P.W. \&Associates (1999). Culture specific and cross-culturally generalizable leadership theories: Are the attributes of charismatic/transformational leadership universally endorsed? Leadership Quarterly, 10, 219-256.

Dessler, G. (2013). Human resource management. Harlow, VB: Pearson.

Dickson, M.W., Den Hartog, D. N, \& Michelson, J.K. (2003) Research on leadership in cross-cultural context: Making progress and raising new questions. Leadership Quarterly, 14, 729-768.

Dorfman, P.W. (2003). International and cross-cultural leadership research. In B.J. Punnet \& O. Shenkar (Eds.) Handbook for international management research, $2^{\text {nd }}$ ed. Ann Arbor, Mi: University of Michigan.

Hofstede, G., (2002). Images of Europe: Past, present and future. In: Warner, M. \& Joynt, P. (Eds). Managing across cultures, (pp. 89-103). London: Thomson.

Hofstede, G. (2001). Culture's consequences. 2nd ed. Thousand Oaks, CA: Sage.

House R.J., Hanges, P.J., Javidan, M., Dorfman, P.W, \& Gupta, V. (2004) Culture, leadership and organizations: The GLOBE study of 62 societies. Thousand Oaks, CA: Sage.

House, R.J. \& Javidan, M. (2004). Overview of GLOBE. In R.J. House, P.J. Hanges, M. Javidan, P.W. Dorfman, V. Gupta, \&Associates (Eds.) Culture, leadership and organizations: The GLOBE study of 62 societies (pp. 9-28). Thousand Oaks: CA: Sage.

Jaeger, A. (1986). Organization Development and National Culture: Where's the Fit?, The Academy of Management Review, 11(1), 178-190.

Janićijević, N. (2013) Organizaciona kultura i menadžment. Beograd: CID Ekonomski fakultet.

Jones G. (2013) Organizational theory, design and change. Harlow, VB: Pearson.

Likert, R. (1961). New patterns of management. New York: McGraw-Hill.

Northouse, P. (2019). Leadership: Theory \& practice. Thousands Oaks, CA: Sage Publishing.

Schuler, R., Jackson, S., Jackofsky, E. \& Slocum, J. (2001). Managing human resource in Mexico: A cultural understanding. In: M. Albrecht, (Ed.) International HRM: managing diversity in the workplace. London: Blackwell.

Sweeney, P \& McFarlin, D. (2015) International management: Strategic opportunities and cultural challenges. London, UK: Routledge.

Thomas, D \& Peterson, M. (2018). Cross-cultural management. Thousands Oaks, CA: Sage.

Yukl, G. (2013). Leadership in organizations. Harlow, VB: Pearson. 